\section{Sound similarity and color-word interference in the Stroop task}

\author{
E. C. DALRYMPLE-ALFORD* \\ Trent University, Peterborough, Ont., Canada
}

The speed with which Ss name the color in which a word is printed is found to depend on the similarity between the sound of the word and the sound of the color names involved in the task. A "priming" interpretation is suggested.

The extent to which a word interferes with the naming of the color in which it is written has been shown to depend on characteristics of the word, such as its commonness (Klein, 1964), its degree of association with a color name (Scheibe, Shaver, \& Carrier, 1967), and its legibility (Gumenik \& Glass, 1970). The possibility that similarity between the pronunciation of the words and that of the required color names may also determine interference in the Stroop task was suggested by A. B. Krist offerson (personal communication). This was considered in Dalrymple-Alford (1972), but it was concluded that the effect, if any, was minimal in that study. Subsequently, results from laboratory exercises in a course run by the writer indicated that, when the interference words were unrelated semantically or associatively to color names, they interfered with color naming much more if they were similar in sound to color names than if they were not. However, some minor methodological defects in the otherwise praiseworthy efforts of the students raised some doubts about the results. The experiment reported below was therefore run with the aim of seeking confirmation of the students' findings.

\section{METHOD}

Latencies of color naming responses to individual Stroop items were obtained by presenting each item in a Gerbrands two-channel tachistoscope which was programmed to display each item for 2 sec. Onset of the display, initiated by the $S$, started an electronic timer which was stopped by S's vocal response, picked up by a voice key.

The Stroop items were prepared using uppercase 20-pt Letraset Project-a-Type (P'T10) in blue, green, and red colors. The words were: (a) color names (red, blue, green);

*I am indebted to Helen O'Connor for collecting the data and assisting with the analysis. Requests for reprints should be addressed to E. C. Dalrymple-Alford, Department of Psychology, University of Guelph, Guelph, Ontario, Canada. (b) words judged to be unrelated to these color names associatively and semantically, as well as in terms of their pronunciation (lid, slot, flown, freed, pun, cat, slur, treat, flaw); (c) words that differed from those in (b) mainly in that their initial sounds were similar if not identical to those of the words "red," "blue," and "green" (run, rat, rid, blur, blot, blow, greed, grown, great); (d) words that differed from those in (b) mainly in that their final sounds were similar to those of the three color names used (led, bed, fed, true, flew, crew, queen, clean, scene). In addition to these sets of words, the letter combinations XWY, JLGHV, and KDMQ were also used. These, together with the 30 words, were prepared once in green, once in red, and once in blue. In the case of the sets (a), (c), and (d), some words were therefore printed in "congruent" colors (e.g., RED, RID, and BED in red; BLUE, BLOT, and FLEW in blue, etc.). A duplicate set of the congruent combinations with the words RED, BLUE, and GREEN were added to increase the number of observations on these. The 102 stimulus items, each on a separate white card, were randomly sorted into nine groups, with the restriction that each group contained at least one letter combination, one color name combination, three combinations with words from Set $b$, three with words from Set $c$, and three from Set $d$. This resulted in three groups having 12 items and six having 11 . A quasirandom ordering of the items within each group was adopted such that no observable bias remained. These within-group orderings were maintained for all Ss, but the groups themselves were ordered in a different random arrangement for each $S$. Preceding these items were seven others whose function was to acquaint $S$ with the requirements of the task. These items consisted of PQR, LMGS, PINK, BLACK, WALL, HOUSE, and STOP, written in red, blue, blue, green, blue, green, and red, respectively.

The Ss were 20 university students who volunteered for the experiment.
RESULTS AND DISCUSSION

Table 1 summarizes the results. There, and in the analysis reported below, only the latencies of correct responses were taken into account, i.e., $94.4 \%$ of all observations, there being approximately $2.6 \%$ errors and $3.0 \%$ cases where the voice key failed to trigger.

The stimuli may be classified into the eight categories shown in Table 1. For each S, two mean latencies were computed for each category, one for the first half of the observations, the other for the second. Where an unequal number $(2 n+1)$ of values occurred, the first half mean was based on the first $(n+1)$ values and the second half mean on the remaining $n$ values. Analysis of variance of these means revealed a significant effect of stimulus category, $F(7,285)=34.82$, $\mathrm{p}<.001$. The "halves" factor, measuring practice effects, was not significant, $\mathrm{F}<1$ (the overall first and second half means were 691 and $681 \mathrm{msec}$, respectively). The Stimulus Category by Halves interaction was not significant, $F(7,285)=1.21$, $p>.05$. The results of the Newman-Keuls test on the means for the eight stimulus categories may be summarized as follows using the numbering in Table 1: (Ib) (IIb, IIIb) (IV, IIIa, V, IIa, Ia), where only categories within the same pair of parentheses are not significantly different from each other at the $1 \%$ level. At the 5\% level, the only additional significant difference to emerge was that between IV and Ia.

These results confirm that when the word in a Stroop item is similar in sound to the name of a color, other than the one in which it is written, naming the color becomes more difficult. Some features of the data suggest that the effects are rather similar to those for words that are associatively or semantically related to color names (Dalrymple-Alford, 1972). Not only is the color of "congruent" items named more quickly than that of "noncongruent" items, but the latencies in the former

Table 1

Mean Color Naming Latencies and Error Percentages

\begin{tabular}{ccc} 
Interference Word & $\begin{array}{c}\text { Latency } \\
\text { (Msec) }\end{array}$ & $\begin{array}{c}\text { Percent } \\
\text { Error }\end{array}$ \\
\hline
\end{tabular}

I Color Names

(a) Congruent

(b) Noncongruent

618

In Intial Sound Similar

(a) Congruent

842

1.7

(b) Noncongruent

641

727

0.6

III Final Sound Similar

(a) Congruent

(b) Noncongruent

656

IV Control Words

714

665

649

0.0

V Control Letters

0.7 
case tend to be smaller than those for "control" words. However, the latter differences were not only not significant in the case of the sound similar stimuli but also very small and, therefore, at best cannot be regarded as being more than suggestive of facilitatory effects. The proportions of errors also show the same trend, though little weight can be given to these data since few errors were made. These trends are not inconsistent with $\mathrm{the}$ view expressed in $D$ alrymple-Alford (1972) and Dalrymple-Alford \& Azkoul (1972) that there may be, as it were, two components of interference arising from the printed word-the need to suppress the "reading" response to the word, and the need to suppress the color name that may be elicited or "primed" by the word. Presumably, only the need to suppress the reading response arises in the case of the "control" word stimuli (IV). In the case of the "noncongruent" combinations (IIb, IIIb), a further component of interference could arise, while for the "congruent" combinations (IIa, IIIa), the color names that may be primed by the written words should facilitate performance. The ordering of mean latencies for these types of stimuli about the mean for the control word combinations is consistent with this view. More convincing is the nature of the Ss' erroneous responses. All but 1 of the 21 cases of errors with the noncongruent color name combinations (Ia) consisted of $S$ saying the printed color name. All of the 18 errors for the noncongruent IIb condition consisted of $S$ saying the color name that had the same initial sound as the written word (e.g. "green" in the case of GROWN, "red" in the case of RAT, and "blue" in the case of BLUR, etc.). Of the 6 errors observed for noncongruent rhyme stimuli (IIIb), 5 were cases in which the $\mathbf{S}$ responded with the color name that rhymed with the printed word (e.g., "green" for QUEEN, "blue" for TRUE, "red" for FED, etc.).

An implication of these results is that a component of one's immediate response to a visually presented word is something akin to an implicit vocal response, perhaps a sort of mapping of phoneme to grapheme (Gibson, Pick, Osser, \& Hammond, 1962). If, as is suggested here, interference with color naming in this task is due to "priming" effects, this would imply that access to words in the "subjective lexicon" may be as readily gained through acoustic-articulatory cues as through semantic ones.

\section{REFERENCES}

DALRYMPLE-ALFORD, E. C. Associative facilitation and interference in the $S$ troop color-word task. Perception \& Psychophysics, 1972, 11, 274-276.

DALRYMPLE-ALFORD, E C. \& AZKOUL, J. The locus of interference in the Stroop and related tasks. Perception \& Psychophysics, 1972, 11, 385-388.

GIBSON, E. J., PICK, A., OSSER, H., \& H AMMOND, M. The role of grapheme-phoneme correspondence in the perception of words. American Journal of Psychology, 1962, 75, 554-570.

GUMENIK, W. E., \& GLASS, R. Effects of reducing the readability of the words in the Stroop color-word test. Psychonomic Science, $1970,20,247-248$

KLEIN, G. S. Semantic power measured through the interference of words with color-naming. American Journal of Psychology, 1964, 17, 576-588.

SCHEIBE, K, E., SHAVER, P. R., \& CARRIER, S. C. Color association values and response interference on variants of the Stroop test. Acta Psychologica, 1967, 26. 286-295. 